\title{
The incidental pulmonary nodule in a child: a conundrum
}

\author{
Peter J. Strouse
}

Received: 11 November 2014 / Accepted: 19 November 2014/Published online: 23 December 2014

(C) Springer-Verlag Berlin Heidelberg 2014

This issue of Pediatric Radiology contains a two-part review by members of the Society for Pediatric Radiology (SPR) Thoracic Imaging Committee on the workup of an incidentally detected solitary pulmonary nodule in a child.

Last year, in a letter to the editor [1], Dr. Paul Thacker outlined the conundrum of the incidental pulmonary nodule in children. Although concise guidelines exist in adults, no such guidelines exist in children. The adult guidelines are often misapplied to children. I have seen this occur within the last month, with the recommendation of a two-phase chest CT to follow up an incidental solitary pulmonary nodule found at the lung base on an abdominal CT performed on a child in an emergency department.

We advanced Dr. Thacker's letter to SPR Thoracic Imaging Committee members and invited them to respond. Since that time, the committee has invested considerable time investigating the subject, discussing it and debating the controversies. The response has proved to be a difficult effort. Little evidence exists on solitary pulmonary nodules in children. As a consequence, no clear and concise guideline can be generated.

Finding an incidental pulmonary nodule in a child, however, is clearly different from finding an incidental pulmonary nodule in an adult. Application of the adult guidelines (Fleischner Society [2]) is not appropriate. The SPR Thoracic Imaging Committee has laid out the available information and outlined why a nodule in a child is different from a nodule in an adult. The bottom line, I believe, is to carefully consider the

\footnotetext{
P. J. Strouse $(\square)$
}

Section of Pediatric Radiology, C. S. Mott Children's Hospital, Department of Radiology, University of Michigan Health System, 1540 E. Hospital Drive, Room 3-231,

Ann Arbor, MI 48109-4252, USA

e-mail: Rad-Ped-Radiol-Journal@med.umich.edu situation and context at hand and to act accordingly. The pediatric radiologist must aid the clinical physician. In turn, the clinical physician must work with the family. The likelihood of an incidental solitary pulmonary nodule in a child representing a primary lung cancer is exceedingly small and essentially nil. The likelihood of an incidental solitary pulmonary nodule in a child representing the presentation of an extrathoracic malignancy in an otherwise healthy child is negligible.

Clinical history, physical examination and laboratory tests matter. A nodule in a child with a history of extrathoracic malignancy, immune compromise, or environmental exposure may hold greater significance. A nodule in a child with evidence of systemic illness on physical examination or laboratory tests may hold greater significance. The finding of multiple nodules is different from that of a solitary nodule.

Along the way, the committee members have touched on a few thorny issues - governmental directives, overutilization, proper CT technique, and response to challenging family expectations. These points illustrate the difficulty of what might be perceived as a simple medical issue.

We thank the SPR Thoracic Imaging Committee for its careful deliberation, review of the literature and discussion of the solitary pulmonary nodule in children.

Conflicts of interest None

\section{References}

1. Thacker PG (2013) The incidental pulmonary nodule: an impetus for guidelines. Pediatr Radiol. doi:10.1007/s00247-013-2762-6

2. MacMahon H, Austin JH, Gamsu G et al (2005) Guidelines for management of small pulmonary nodules detected on CT scans: a statement of the Fleischner Society. Radiology 237: 395-400 